\title{
Surface Tension, Density and Viscosity Studies on the Associative Behaviour of Oxyethylene-Oxybutylene Diblock Copolymers in Water at Different Temperatures
}

\author{
Abbas Khan ${ }^{1,2}$, Iram Bibi ${ }^{1}$, Seemab Pervaiz ${ }^{3}$, Khalid Mahmood $^{3}$, Mohammad Siddiq ${ }^{*}$ \\ ${ }^{1}$ Department of Chemistry, Quaid-I-Azam University, Islamabad, Pakistan \\ ${ }^{2}$ Department of Chemistry, Abdul Wali Khan University, Mardan, Pakistan \\ ${ }^{3}$ Department of Chemistry, Hazara University, Mansehra, Pakistan \\ Email: "m_sidiq12@yahoo.com
}

Received October 4, 2011; revised December 1, 2011; accepted December 19, 2011

\begin{abstract}
The associative properties of methoxy $\left(\mathrm{CH}_{3} \mathrm{O}-\right)$ ended $\mathrm{E}_{58} \mathrm{~B}_{11}$ and hydroxyl (-OH) ended $\mathrm{E}_{56} \mathrm{~B}_{19}$ oxyethylene-oxybutylene diblock copolymers in aqueous solution at different temperature are reported in this paper. For both copolymers, $\mathrm{E}$ represents an oxyethylene (-[ $\left.\left[\mathrm{CH}_{2} \mathrm{CH}_{2} \mathrm{O}\right]-\right)$ unit and $\mathrm{B}$ an oxybutylene $\left(-\left[\mathrm{CH}\left(\mathrm{C}_{2} \mathrm{H}_{5}\right) \mathrm{CH}_{2} \mathrm{O}\right]-\right)$ unit while the subscripts denote the number average block length. Surface tension measurements were used to find out surface excess concentrations $\left(\Gamma_{\mathrm{m}}\right)$, area per molecule $\left(\mathrm{a}_{1}^{s}\right)$ at air/water interface and Gibbs free energy for adsorption $\left(\Delta \mathrm{G}_{\mathrm{ads}}^{\circ}\right)$ for the pre-micellar region at four temperatures. Likewise thermodynamic parameters of micellization such as, critical micelle concentrations (CMC), enthalpy of micellization $\left(\Delta \mathrm{H}_{\text {mic }}^{\circ}\right)$, standard free energy of micellization $\left(\Delta \mathrm{G}_{\text {mic }}^{\circ}\right)$ and entropy of micellization $\left(\Delta \mathrm{S}_{\text {mic }}^{\circ}\right)$, were also obtained using surface tension measurements. Solution densities were used to determine the partial specific volume of micelle $\left(\bar{V}_{\text {mic }}\right)$ and micellar density $\left(\rho_{\text {mic }}\right)$. Dilute solution viscosities have been used to estimate the intrinsic viscosities $[\eta]$, solute-solvent interaction parameter $\left(\mathrm{K}_{\mathrm{H}}\right)$ and hydration value of micelle $\left(\mathrm{W}_{\mathrm{h}}\right)$ at various temperatures. The effect of temperature on the micelle properties is also discussed.
\end{abstract}

Keywords: Block Copolymers; Adsorption; Micellization; Surface Tension; Density; Viscosity

\section{Introduction}

Due to their academic as well as promising industrial applications, block copolymers self assembly in selective solvents has been drawn considerable attention of physicist and chemists in the recent decades. Self assembled aggregates of various morphologies have been reported ranging from spherical micelles to vesicle, tubules and complex super-aggregates. Such morphologies can be well tuned by relative block length, solvent composition, polymer concentration, additives and temperature [1]. Polymeric micelles are core shell structures formed through the self assembly of amphiphilic polymers in a solvent that is hostile toward either moiety. In aqueous media, these micelles have an internal hydrophobic core surrounded by an outer hydrophilic corona which shields the nonaqueous core from external medium. This particular type of micelles has been extensively studied with a particular attention toward their ability to improve aqueous solubility of hydrophobic therapeutic agents [2].

${ }^{*}$ Corresponding author.
The micellization in aqueous solutions can be initiated at a given temperature by increasing the concentration beyond the critical micelle concentration (CMC). In dilute solutions, it forms spherical micelle with a "core" made up of hydrophobic block and a "corona" composed of hydrophilic block. In concentrated solutions, a variety of super-structures like body-centered cubic (bcc) or face-centered cubic (fcc) arrays of spherical micelles, hexagonal arrays of elongated micelles and lamellar structures can be formed [3-5]. Some of these aggregates are bilayered and biomimetic [6]. The various morphologies of micelle/aggregates would have potential applications in nanostructures [7], nanomaterials [8], photonic crystals [9], drug delivery systems [10], artificial tissues, and soft biomaterials [11]. Due to the large scale importance of block copolymer self-assembly, it is very essential to understand the shape, structure, size, and growth of aggregates formation by corresponding systems [12].

Micellar behaviour of aqueous solutions of block copolymers with hydrophilic block of oxyethylene (E) units, - $\left[\mathrm{CH}_{2} \mathrm{CH}_{2} \mathrm{O}\right]$-, and hydrophobic block of oxybutylene (B) 
units, - $\left[\mathrm{CH}\left(\mathrm{C}_{2} \mathrm{H}_{5}\right) \mathrm{CH}_{2} \mathrm{O}\right]$ - have also been studied in detail $[3,13,14]$. A number of experimental techniques have been applied to investigate the self-assembly of block copolymer [15-19]. To get the desirable and fairly precise properties for different applications, the polymer block length, block compositions, block nature and block architectures can be adjusted. Such desirable properties can also be obtained by altering the solution composition by using co-solvent and co-solutes, but sometime the effect of these additives may also be less advantageous [3, 13,20-24].

Limited studies have been carried out on the micelle properties of oxyethylene-oxybutylene block copolymers using fundamental and easily available techniques like surface tensiometry, densitometry and viscometry. The present work has been carried out to see the application of these fundamental experimental techniques to the association behaviour of two E-B block copolymers with different $\mathrm{E} / \mathrm{B}$ block ratio and hydrophilic ends at various solution temperatures.

\section{Introduction}

\subsection{Preparation and Characterization of the Copolymers}

The block copolymers were synthesized using sequential anionic polymerization in tetrahydrofuran of ethylene oxide, followed by butylene oxide. Standard vacuum line techniques were employed for the transfer of monomers. The initiator was prepared by dissolving potassium metal in a five-fold excess of 2-(2-methoxyethoxy)ethanol under nitrogen. A specific amount of ethylene oxide was transferred under vacuum into an ampoule containing initiator $(0.77 \mathrm{~g})$. The temperature was increased from ambient to $80^{\circ} \mathrm{C}$ over 8 days. Then the desired amount of but-1-ene oxide was transferred into the ampoule under vacuum. The temperature was increased from ambient to $80^{\circ} \mathrm{C}$ over $10-12$ days. The preparation and characterization of such copolymers in detailed manner has been reported earlier [25]. Nuclear magnetic resonance (NMR) end-group analysis gave average composition of $\mathrm{CH}_{3} \mathrm{O}$ $\mathrm{E}_{58} \mathrm{~B}_{11}$ and $\mathrm{HO}-\mathrm{E}_{56} \mathrm{~B}_{19}$. Gel permeation chromatography (GPC) was used for the molar mass distribution of the copolymer, which indicated narrow distribution $\left(M_{\mathrm{w}} / M_{\mathrm{n}} \approx\right.$ 1.02 ), where $M_{\mathrm{w}}$ and $M_{\mathrm{n}}$ are the mass average and number average molar masses respectively. Absolute values of number-average molar mass, $M_{\mathrm{n}}$ were obtained by using ${ }^{13} \mathrm{C}$ NMR. Molecular characteristics of the block copolymers used in this study are given in Table $\mathbf{1}$.

\subsection{Surface Tension Measurements}

The surface tension, $(\gamma)$ of dilute aqueous copolymer solutions in the temperature range of $20^{\circ} \mathrm{C}-50^{\circ} \mathrm{C}$ was
Table 1. Molecular characteristics of the block copolymers used in this study.

\begin{tabular}{cccc}
\hline $\begin{array}{c}\text { Polymer } \\
\text { Sample }\end{array}$ & $\mathbf{M}_{\mathbf{w}} /(\mathbf{g} / \mathbf{m o l})$ & $\mathbf{M}_{\mathbf{n}} /(\mathbf{g} / \mathbf{m o l})$ & $\mathbf{M}_{\mathbf{w}} / \mathbf{M}_{\mathbf{n}}$ \\
\hline $\mathrm{E}_{58} \mathrm{~B}_{11}$ & 3445 & 3344 & 1.03 \\
$\mathrm{E}_{56} \mathrm{~B}_{19}$ & 3909 & 3832 & 1.02 \\
\hline
\end{tabular}

determined by detachment of platinum ring $(4 \mathrm{~cm}$ circumference), using a torsion balance (White Elec. Inst. Co. Ltd., Model OS). The instrument was kept under controlled conditions so that to avoid from vibration and draught. The sample measuring cell (containing copolymer solution) was connected to a circulating water bath to keep the desired temperature constant with $\pm 0.2^{\circ} \mathrm{C}$. Prior to any measurement, the platinum ring was cleaned by washing with dilute $\mathrm{HCl}$ followed by doubled distilled water and then dried. For each copolymer, a stock solution $\left(2 \mathrm{~g} \cdot \mathrm{dm}^{-3}\right)$ was prepared in deionized and doubled distilled water and further diluted as required. For any new measurement, the copolymer solution was first equilibrated at lowest temperature and then surface tension, $\gamma$ was measured for every fifteen minutes until consistent readings were obtained. Then the temperature was raised and the solution was re-equilibrated for (30 - 40 minutes) and the measurement procedure was repeated. During experiment the accuracy of instrument was checked by frequent determination of the surface tension of deionized water. Each experiment was repeated three or more times. After getting the surface tension data for about thirty dilutions for each copolymer solution at a given temperature, the plots of surface tension $(\gamma)$ versus $\log \mathrm{C}$ (where $\mathrm{C}$ is the concentration of copolymers the in $\mathrm{g} \cdot \mathrm{dm}^{-3}$ ) were used for estimation of the critical micelle concentration, CMC of the polymer. The CMC, was assigned to the concentration at and above which the surface tension remain constant [3,21,26-28].

\subsection{Viscosity and Density Measurements}

The viscosity and density measurements of block copolymers solutions in deionized water were made by using Stabinger Viscometer G2 (SVM 3000/G2) supplied by Anton Paar. SVM 3000 combines the accuracy of conventional capillary viscometers with the speed and ease of use of Anton Paar's world-leading digital density meters. The instrument has an automatic temperature control system maintained by Peltier effect with a resolution of $\pm 0.001^{\circ} \mathrm{C}$. The measuring temperature was in the range of $20^{\circ} \mathrm{C}-50{ }^{\circ} \mathrm{C}$. Each time, the syringe used to inject sample and sample cell were thoroughly washed with doubled distilled and deionized water to get more accurate results. In the same way the accuracy of instrument was checked by frequent determination of the viscosity and density of deionized water and some standard 
samples. The instrument directly gave the values of density, dynamic viscosity and kinematics viscosity. These results were, then further used for the calculations of intrinsic viscosities; solute-solvent interaction parameter and hydration value of micelle were obtained from viscosity measurements. Solution densities were used for the calculations of partial specific volume of micelle and micellar density.

\section{Results and Discussion}

\subsection{Thermodynamic Parameters of Micellization and Adsorption at Air/Water Interface}

The onset of micellization (critical micelle concentration) as well as adsorption characteristics of block copolymers at the air/water interface can be well studied using surface tension measurements [29]. The dependence of surface tension $(\gamma)$ on copolymer concentrations $(\log C)$ for both copolymers in aqueous solutions at different temperatures is shown in Figures 1 and 2. All plots of surface tension $(\gamma)$ versus logarithm of copolymer concentration $(\log C)$ for aqueous solutions in both figures show a familiar polymeric surfactant behaviour. That is, by increasing polymer amount in solution led to sharp decrease in surface tension up to a specific concentration and beyond which no prominent decrease in surface tension was observed. The sharp decrease in surface tension in the first region of the plots is due to the adsorption of polymer at air/water interface. This regular decrease in surface tension of solution with polymer concentration continues till the completion of Gibbs monolayer. After which there is no more prominent change in the surface tension with concentration, which means that further polymer unimers go into the bulk of solution and these unimers associate in the form of self-assembled structure called micelle. Thus the concentration of polymer at or above which the surface tension versus concentration profile become constant is called the critical micelle concentration (CMC). Graphically the values of CMC were obtained from the point of intersection of two straight lines in the surface tension-concentration plots. One straight line was drawn where the surface tension drastically decreases with copolymer concentration and the other from the region where it becomes nearly constant $[3,30,31]$. In some cases the surface tension does not remain fairly constant after CMC for block copolymers solutions; this is due to the formation of dimers and trimers or the lack of large micelles [32]. Moreover the non constant behaviour of surface tension after CMC can also reflect the dynamic nature of the micellization. The values of the surface tension at $\mathrm{CMC}, \gamma_{\mathrm{CMC}}$, for both copolymers are listed in Table 2.

For both of these copolymers, the critical micelle concentration, $\mathrm{CMC}$, decrease with increasing temperature.

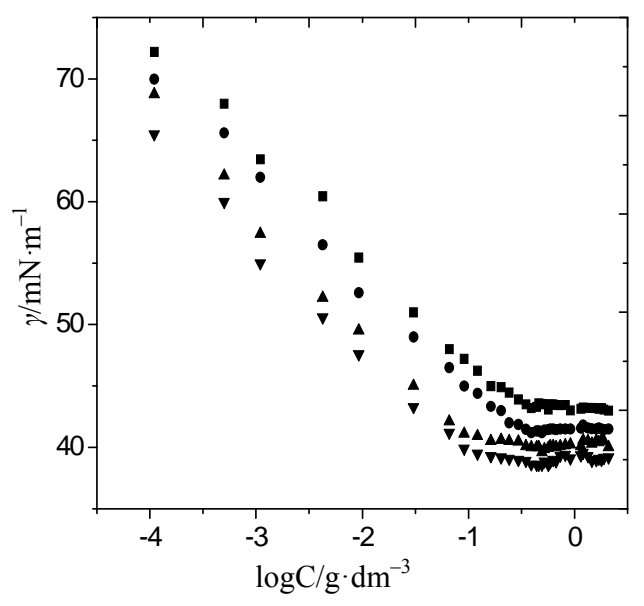

Figure 1. Typical Plots of surface tension $(\gamma)$ as a function of logarithmic concentration $(\log C)$ for aqueous solutions of $\mathrm{E}_{58} \mathrm{~B}_{11}$ at (घ) $20^{\circ} \mathrm{C},(\bullet) 30^{\circ} \mathrm{C},(\Delta) 40^{\circ} \mathrm{C}$ and $(\nabla) 50^{\circ} \mathrm{C}$.

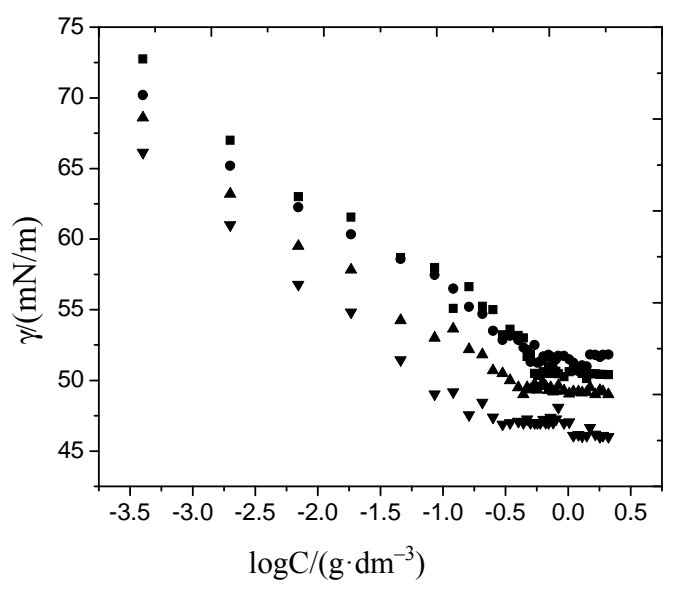

Figure 2. Typical Plots of surface tension $(\gamma)$ as a function of logarithmic concentration $(\log C)$ for aqueous solutions of $\mathrm{E}_{56} \mathrm{~B}_{19}$ at (घ) $20^{\circ} \mathrm{C},(\bullet) 30^{\circ} \mathrm{C},(\Delta) 40^{\circ} \mathrm{C}$ and $(\nabla) 50^{\circ} \mathrm{C}$.

The effect can be assigned to the increase in dehydration of the unimers and hence increases their hydrophobic character. However the effect of temperature on CMC is complex, temperature increase causes decrease in hydration of hydrophilic group, which favors micellization. However, temperature increase also causes disruption of the structured water surrounding the hydrophobic group, an effect that disfavors micellization. The relative magnitude of these two opposing effects, therefore, determines whether the CMC increases or decreases over a particular temperature range [27]. In most cases of nonionic surfactants, increase in temperature favour micellization and aggregation process while opposite situation can be seen in case of ionic amphiphiles because the solubility of ionic surfactant enhances at higher temperature and repulsion between the ionic head groups may occur $[4,7,16,26-38]$. In case of PEO-PBO block copolymers, it is expected that higher is the content of hydro- 
Table 2. Critical Micelle Concentrations (CMC), Surface tensions at CMC $\left(\gamma_{\mathrm{CMC}}\right)$, Free Energy of Micellization ( $\left.\Delta G_{\mathrm{mic}}^{\circ}\right)$, Enthaly, $\left(\Delta H_{\text {mic }}^{\circ}\right)$ and Entropy of Micellization $\left(\Delta S_{\text {mic }}^{\circ}\right)$ for the oxyethylene-oxybutylene diblock and triblock copolymers in aqueous solutions at Different Temperatures.

\begin{tabular}{ccccccc}
\hline Polymer & $\mathbf{T} /{ }^{\circ} \mathbf{C}$ & $\mathbf{C M C} /(\mathbf{g} / \mathbf{L})$ & $\gamma_{\mathbf{C M C}} /(\mathbf{m N} / \mathbf{m})$ & $\Delta \mathrm{G}_{\text {mic }}^{\circ} /(\mathbf{K J} / \mathbf{m o l})$ & $\Delta \mathrm{H}_{\text {mic }}^{\circ} /(\mathbf{K J} / \mathbf{m o l})$ & $\Delta \mathrm{S}_{\text {mic }}^{\circ} /(\mathbf{K J} / \mathbf{m o l} \cdot \mathbf{K})$ \\
\hline $\mathrm{E}_{58} \mathrm{~B}_{11}$ & 20 & 0.35 & 43.60 & -19.37 & 37.34 & 0.193 \\
& 30 & 0.32 & 41.70 & -20.24 & 37.32 & 0.190 \\
& 40 & 0.12 & 40.45 & -23.49 & 37.35 & 0.194 \\
& 50 & 0.10 & 39.25 & -24.73 & 37.34 & 0.192 \\
$\mathrm{E}_{56} \mathrm{~B}_{19}$ & 20 & 0.60 & 51.40 & -18.07 & 21.78 & 0.136 \\
& 30 & 0.53 & 51.20 & -19.00 & 21.78 & 0.134 \\
& 40 & 0.40 & 49.30 & -20.36 & 21.78 & 0.134 \\
& 50 & 0.26 & 47.00 & -22.16 & 21.78 & 0.136 \\
\hline
\end{tabular}

Estimated uncertainities: $\pm 10 \%$ in $\mathrm{CMC} ; \pm 4 \%$ in $\gamma_{\mathrm{CMC}} ; \pm 2 \%$ in $\Gamma_{\mathrm{m}} ; \pm 3 \%$ in a ${ }_{1}^{\mathrm{s}} ; \pm 4 \%$ in $\pi_{\mathrm{CMC}} ; \pm 4 \%$ in $\quad \Delta G_{\text {ads }}^{\circ}, \Delta G_{\text {mic }}^{\circ}, \Delta H_{\text {mic }}^{\circ}$ and $\quad \Delta S_{\text {mic }}^{\circ}$.

phobic PBO block lower may be the CMC. However in the present case, at a given temperature $\mathrm{E}_{58} \mathrm{~B}_{11}$ has smaller $\mathrm{CMC}$ as compared to $\mathrm{E}_{56} \mathrm{~B}_{19}$ having longer $\mathrm{PBO}$ block. This effect arise because $\mathrm{E}_{58} \mathrm{~B}_{11}$ has methoxy group at the end while $\mathrm{E}_{56} \mathrm{~B}_{19}$ has hydroxyl, group at the hydrophilic end. The presence of $-\mathrm{OCH}_{3}$ end group increase the hydrophobic character of $\mathrm{E}_{58} \mathrm{~B}_{11}$ as compared to the $-\mathrm{OH}$ group in case of $\mathrm{E}_{56} \mathrm{~B}_{19}$. The more hydrophobic character due to the end group is further verified from the lower value of $\gamma_{\text {CMC }}$ for $E_{58} B_{11}$ as compared to $E_{56} B_{19}$ at a given temperature (Table 2).

A number of well established models can be used to explain the association behaviour of amphiphilic compounds. However, using the earlier established concepts [38], we have applied the closed association model. According to this model, for micellization with narrow distribution of aggregation number $(\mathrm{N})$, the equilibrium between copolymers unimer molecules (A) and micelles $\left(A_{N}\right)$ can be written as (where the concentration in mole $\mathrm{dm}^{-3}$ ) [38];

$$
\mathrm{A} \Leftrightarrow[1 / N] \mathrm{A}_{\mathrm{N}} \mathrm{K}_{\mathrm{c}}=[\mathrm{A}]_{\mathrm{eq}} 1 / N /[\mathrm{A}]_{\mathrm{eq}}
$$

Hall in his detailed study showed that when association number $\mathrm{N}_{\mathrm{w}}$ is very large, then the equation becomes [38];

$$
\begin{array}{r}
\mathrm{K}_{\mathrm{c}}=1 /[\mathrm{A}]_{\mathrm{eq}} \\
\mathrm{K}_{\mathrm{c}}=1 / \mathrm{CMC}
\end{array}
$$

where $[\mathrm{A}]_{\mathrm{eq}}$ is considered to be the critical micelle concentration (CMC). The change in standard Gibbs free energy of micellization per mole of copolymer unimer can be related to $\mathrm{CMC}$ by applying some important relationship [38];

$$
\begin{gathered}
\Delta G_{\mathrm{mic}}^{\circ}=-\mathrm{RT} \ln \mathrm{K}_{\mathrm{c}} \\
\Delta G_{\mathrm{mic}}^{\circ}=\mathrm{RT} \ln \mathrm{CMC}
\end{gathered}
$$

or

$$
\Delta G_{\text {mic }}^{\circ}=\mathrm{RT} \ln (\mathrm{CMC} / \mathrm{W})
$$

$\mathrm{R}$ is Gas constant, $\mathrm{T}$ is Absolute temperature and $\mathrm{W}$ is the molarity of pure water

The standard enthalpy change of micellization is given approximately by [34-38];

$$
\Delta H_{\text {mic }}^{\circ}=\frac{-\mathrm{Rd}\left[\ln \mathrm{K}_{\mathrm{c}}\right]}{\mathrm{d}(1 / T)}
$$

To relate $\Delta H_{\text {mic }}^{\circ}$ to $\mathrm{CMC}$, Equation (5) can modified to the following relation by putting the value of $\mathrm{K}_{\mathrm{c}}$ from Equation (2) and we can get;

$$
\Delta H_{\text {mic }}^{\circ}=\frac{\operatorname{Rd}[\ln \mathrm{CMC}]}{\mathrm{d}(1 / T)}
$$

Using Equation (6), the standard change in enthalpy of micellization for both copolymers was obtained from the slope of the plots of $\operatorname{lnCMC}$ versus inverse of temperature, such a typical plot for $\mathrm{E}_{58} \mathrm{~B}_{11}$ is shown in Figure 3 . While the entropy of micelles formation was calculated from the well known thermodynamic equation;

$$
\Delta S_{\text {mic }}^{\circ}=\left(\Delta H_{\text {mic }}^{\circ}-\Delta G_{\text {mic }}^{\circ}\right) / T
$$

For both copolymers the calculated values of thermodynamic parameters for micellization are given in the Table 2. It can be seen that the $\Delta G_{\text {mic }}^{\circ}$ values for each copolymer are negative and become more negative with increase in temperature indicating the spontaneous nature of the micellization process at all temperatures. Relatively more negative behaviour of $\Delta G_{\text {mic }}^{\circ}$ values for 


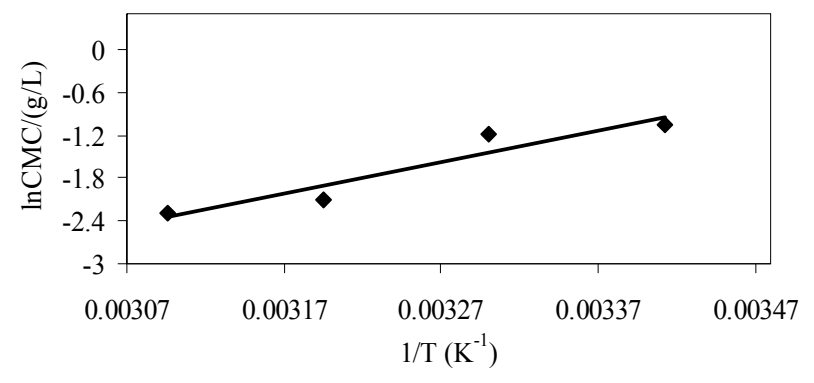

Figure 3. Typical plot of logarithm of CMC (InCMC) versus inverse of temperature for aqueous solutions of $E_{58} B_{11}$.

$\mathrm{E}_{58} \mathrm{~B}_{11}$ as compared to $\mathrm{E}_{56} \mathrm{~B}_{19}$ indicates the more hydrophobic nature of the former due to the presence of methoxy end group. Thus our result suggest that anything for example longer hybrophobic block length, more hydrophobic end group and increase in temperature raise the hydrophobicity of the copolymer and hence increasing the association ability of the polymer. The enthalpy of micellization, $\Delta H_{\text {mic }}^{\circ}$ is positive for both copolymers and at all temperatures, this indicates the endothermic nature of micellazation which is driven by the decreasing polarity of $\mathrm{E}$ and B-chains in water. Further it means that energy is required to overcome the interactions of water with copolymer's unimers and to bring them from hydrophilic bulk into relatively hydrophobic core of the micelle. It can be seen that $\Delta H_{\text {mic }}^{\circ}\left(\mathrm{E}_{58} \mathrm{~B}_{11}\right)>\Delta H_{\text {mic }}^{\circ}$ $\left(\mathrm{E}_{56} \mathrm{~B}_{19}\right)$, showing better micellar ability for the former as compared to the latter one, again the effect can be attributed to the more hydrophobic end group. The change in standard entropy of micellization, $\Delta S_{\text {mic }}^{\circ}$ for each polymer sample is positive and having nearly constant values at all temperatures. During the process of micellization, the entropy change is always positive, it is because of two reasons 1) Structured water molecules is affected and destroyed, as hydrophobic blocks are removed from the aqueous bulk to the interior of micelle at the interface. 2) It also suggests that freedom of hydrophobic block in the interior of micelle is increased. Nearly same value of $\Delta S_{\text {mic }}^{0}$ at all temperature suggests that the rapid increase in association number at higher temperature may make the micelle more compact and hence less freedom for B-block within the core of micelle [29]. Again it can be seen that at all temperature

$\Delta S_{\text {mic }}^{\circ}\left(\mathrm{E}_{58} \mathrm{~B}_{11}\right)>\left(\mathrm{E}_{56} \mathrm{~B}_{19}\right) \cdot \Delta S_{\text {mic }}^{\circ}$.

In addition to micellar thermodynamic parameter, surface tensiometric measurements have also been applied to get information about the adsorption of the copolymer at air/water interface. For this reason, the pre-micellar region (initial linear decrease) of surface tension $(\gamma)$ versus $\operatorname{logarithm}$ of copolymer concentration $(\log \mathrm{C})$ plots was used as shown in Figures $\mathbf{1}$ and 2. Such study of the interfacial properties of amphiphilic block copolymers in solutions provides us information about solute-solute and solute-solvent interactions [29]. To calculate the surface excess concentration $\left(\Gamma_{\mathrm{m}}\right)$, of the copolymer at the air/water interface as compared to that in bulk of solution, we have applied Gibbs adsorption isotherm [21,33];

$$
\Gamma_{m}=-\frac{1}{2.303 R T}\left(\frac{\partial \gamma}{\partial \log \mathrm{C}}\right)_{T}
$$

Equation (8) shows that the slope of the linear part (pre-micellar part) of surface tension $(\gamma)$ versus $\log C$ plots can be used for this purpose. For the pre-micellar region below the $\mathrm{CMC}$, it is generally assumed that that the concentration of copolymer unimers in the bulk solution is negligible compared to their concentration at the air/water interface. Using this concept, the value of surface excess concentration $\left(\Gamma_{\mathrm{m}}\right)$, can be used to estimate the area per polymer molecule in angstroms in the surface monolayer from the relationship [27];

$$
a_{1}^{s}=\frac{10^{16}}{N_{A} \Gamma_{m}}
$$

where $\mathrm{R}$ is $8.314 \mathrm{~J} \cdot \mathrm{mol}^{-1} \cdot \mathrm{K}^{-1}, \mathrm{~T}$ is absolute temperature in Kelvin, $\frac{\partial \gamma}{\partial \log C}$ is the slope of linear portions of the $\gamma$ vs $\log C$ plots, $\mathrm{N}_{\mathrm{A}}$ is Avogadro's number and $\Gamma_{\mathrm{m}}$ is in moles $/ \mathrm{cm}^{2}[32,33]$. The values of surface excess concentration $\left(\Gamma_{\mathrm{m}}\right)$, the area per molecule at air/water interface $\left(a_{1}^{s}\right)$ and other thermodynamic parameters of adsorption are presented in the Table 3. Within the range of experimental error, both surface excess concentration $\left(\Gamma_{\mathrm{m}}\right)$ and the area per molecule at air/water interface $\left(a_{1}^{s}\right)$ show a regular trend with raising temperature. A regular decrease in $\Gamma_{\mathrm{m}}$ was observed for both copolymers with temperature, the effect can be attributed to the expansion of unimers with increasing temperature and hence less number of polymer's unimers can be accommodated at fixed air/water interface. The expansion of polymer with temperature is also reflected from the corresponding increase in area at air/water interface $\left(a_{1}^{s}\right)$ (Table 3). Soni et al. have also reported an increase in $a_{1}^{s}$ with increase in temperature for silicone based surfactants in aqueous media [36]. The dehydration of PEO group is also expected at higher temperature and hence decreasing the tendency of copolymer to locate at air/water interface [33]. At a given temperature the value of $\Gamma_{m}$ for $E_{58} B_{11}$ is larger as compared to $\mathrm{E}_{56} \mathrm{~B}_{19}$; the effect can be attributed to the overall molecular weight of the copolymer; that is more number of polymer's unimers can be accommodated for low molecular weight polymer as compared to polymer with higher molecular weight. This effect is also verified from the larger values of $a_{1}^{s}$ for $\mathrm{E}_{56} \mathrm{~B}_{19}$ as compared to $\mathrm{E}_{58} \mathrm{~B}_{11}$. This relative expansion in surface area may originate from the higher flexibility of the hydrophobic part of the molecule at higher temperature and 
Table 3. Surface Excess Concentrations $\left(\Gamma_{\mathrm{m}}\right)$, Area Per Copolymer Molecules $\left(a_{1}^{s}\right)$, Surface Pressure $\left(\pi_{\mathrm{CMC}}\right)$, Free Energy of Adsorption ( $\Delta G_{\text {ads }}^{\circ}$ ), Enthaly, $\left(\Delta H_{\text {ads }}^{\circ}\right)$ and Entropy of Adsorption ( $\Delta S_{\text {ads }}^{\circ}$ ) for the oxyethylene-oxybutylene diblock copolymers in aqueous solutions at Different Temperatures.

\begin{tabular}{|c|c|c|c|c|c|c|c|}
\hline Polymer & $\mathrm{T} /{ }^{\circ} \mathrm{C}$ & $\Gamma_{\mathrm{m}} \times 10^{10} / \mathrm{mol} \cdot \mathrm{cm}^{-2}$ & $a_{1}^{s} /\left(\AA^{2}\right)$ & $\pi_{\mathrm{CMC}} /(\mathbf{m N} / \mathbf{m})$ & $\Delta G_{\text {ads }}^{\circ} /(\mathrm{KJ} / \mathbf{m o l})$ & $\Delta H_{\mathrm{ads}}^{\circ} /(\mathbf{K J} / \mathbf{m o l})$ & $\Delta S_{\text {ads }}^{\circ} /(\mathbf{K J} / \mathbf{m o l} \cdot \mathbf{K})$ \\
\hline \multirow[t]{4}{*}{$\mathrm{E}_{58} \mathrm{~B}_{11}$} & 20 & 1.52 & 109.0 & 29.15 & -38.55 & 37.86 & 0.26 \\
\hline & 30 & 1.51 & 110.0 & 29.48 & -40.00 & 38.58 & 0.26 \\
\hline & 40 & 1.50 & 111.0 & 29.50 & -42.77 & 38.85 & 0.26 \\
\hline & 50 & 1.41 & 117.0 & 30.65 & -46.47 & 37.76 & 0.26 \\
\hline \multirow[t]{4}{*}{$\mathrm{E}_{56} \mathrm{~B}_{19}$} & 20 & 1.13 & 147.0 & 21.35 & -37.00 & 41.87 & 0.26 \\
\hline & 30 & 1.01 & 164.0 & 19.98 & -38.78 & 42.32 & 0.26 \\
\hline & 40 & 1.01 & 164.0 & 20.65 & -40.80 & 43.45 & 0.26 \\
\hline & 50 & 0.99 & 168.0 & 22.90 & -45.29 & 43.77 & 0.26 \\
\hline
\end{tabular}

Estimated uncertainities $\pm 3 \%$ in $\Gamma_{\mathrm{m}} ; \pm 4 \%$ in $\mathrm{a}_{1}^{\mathrm{s}} ; \pm 3 \%$ in $\pi_{\mathrm{CMC}} ; \pm 5 \%$ in $\Delta G_{\text {ads }}^{\circ}, \Delta H_{\text {ads }}^{\circ}$, and $\Delta S_{\text {ads }}^{\circ}$.

also due to the expansion of the hydrophilic E-block. For both copolymers at all temperatures, the values of $a_{1}^{s}$ ranging from 98 to 168 Angstrom square, indicating the close packing and perpendicular orientations of the copolymer unimers at air/water interface due to greater interactions of the longer hydrophilic blocks (head groups) with each others as well as with the interface [35]. Table 3 summarizes various thermodynamic parameters for adsorption at air/water interface. The Gibbs free energy of adsorption, $\Delta G_{\mathrm{ads}}^{\circ}$ was calculated from the values of surface excess concentration $\left(\Gamma_{\mathrm{m}}\right)$, surface pressure at critical concentration $\left(\pi_{\mathrm{CMC}}\right)$ and Gibbs free energy of micellization ( $\Delta G_{\text {mic }}^{\circ}$ ) by applying the relation [27,29-39].

$$
\Delta G_{\mathrm{ads}}^{\circ}=\Delta G_{\mathrm{mic}}^{\circ}-\frac{\pi_{\mathrm{CMC}}}{\Gamma_{m}}
$$

The surface pressure at critical concentration $\left(\pi_{C M C}\right)$ is related to the effectiveness of surface active molecule and was calculated as $\pi_{\mathrm{CMC}}=\gamma_{\circ}-\gamma_{\mathrm{CMC}}$ where $\gamma_{\circ}$ and $\gamma_{C M C}$ are the values of surface tension of pure water and that of the solutions at CMC [21,33,37]. At a specific temperature, the higher value of $\pi_{\mathrm{CMC}}$ for $\mathrm{E}_{58} \mathrm{~B}_{11}$ as compared to $\mathrm{E}_{56} \mathrm{~B}_{19}$ reflects the increase in hydrophobicity and hence lowering in hydrophilicity of end group of the hydrophilic block due to the presence of methoxy group in case of $\mathrm{E}_{58} \mathrm{~B}_{11}$. In other words more reduction in $\gamma_{\mathrm{CMC}}$ is observed for $\mathrm{E}_{58} \mathrm{~B}_{11}$ as compared to $\mathrm{E}_{56} \mathrm{~B}_{19}$ (Table 2). The standard entropy ( $\Delta S_{\text {ads }}^{\circ}$ ) was obtained from the slope of $\Delta G_{\mathrm{ads}}^{\circ}$ vs temperature (in Kelvin) plot as shown in Figure 4, while the enthalpy, $\left(\Delta H_{\text {ads }}^{\circ}\right)$ was deduced from the well known thermodynamic relation [36].

$$
\Delta H_{\mathrm{ads}}^{\circ}=\Delta G_{\mathrm{ads}}^{\circ}+T \Delta S_{\mathrm{ads}}^{\circ}
$$

Like $\Delta G_{\text {mic }}^{\circ}$, Gibbs free energy of adsorption, $\Delta G_{\text {ads }}^{\circ}$ for both copolymers at all temperature is negative showing that adsorption is also spontaneous in nature. It is

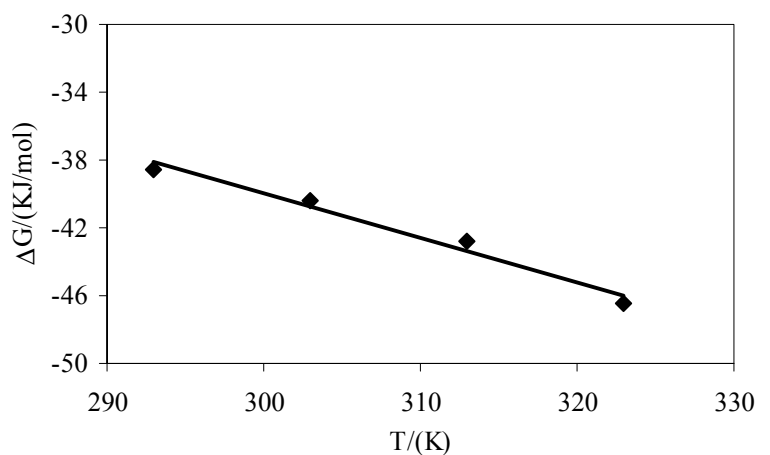

Figure 4. Typical plot of Gibbs free energy of adsorption versus temperature for aqueous solutions of $E_{58} B_{11}$.

also clear that $\Delta G_{\text {ads }}^{\circ}$ become more negative at higher temperature, indicating easier adsorption because at higher temperature dehydration of hydrophilic group occurs and thus less energy is required for adsorption [37]. Moreover, , $-\Delta G_{\mathrm{ads}}^{\circ}>\Delta G_{\mathrm{mic}}^{\circ}$, indicating that transferring the copolymers to the surface is faster as compared to micelle formation. Positive values of $\Delta H_{\text {ads }}^{\circ}$ and $\Delta S_{\text {ads }}^{\circ}$ suggest that adsorption at air/water interface is endothermic and entropy driven. Positive $\Delta S_{\text {ads }}^{\circ}$ means that freedom of polymer unimers and hence movements occur at air/water interface. Higher value of $\Delta S_{\text {ads }}^{\circ}$ as compared to $\Delta S_{\text {mic }}^{\circ}$ reflect the greater freedom of unimers at interface than in the hydrophobic core of the micelle. Likewise, the enthalpy of adsorption $\Delta H_{\text {ads }}^{\circ}$ is also positive which means that energy is required to break the bonds between PEO head groups of the unimers and water in transferring them to the interface. $\Delta H_{\text {ads }}^{\circ}>\Delta H_{\text {mic }}^{\circ}$ meaning that greater number of bonds between unimers and water have to be broken in adsorption as compared to micellization. It can be further seen that $\Delta H_{\text {ads }}^{\circ}\left(\mathrm{E}_{56} \mathrm{~B}_{19}\right)$ is higher as compared to $\Delta H_{\mathrm{ads}}^{\circ}\left(\mathrm{E}_{58} \mathrm{~B}_{11}\right)$ showing the effect of block the length and hence overall molecular weight of the copolymers. 


\subsection{Micellar Parameters from Density and Viscosity}

To obtain the partial specific volume of the micelles $\left(\bar{V}_{\text {mic }}\right)$ and micellar density $\left(\rho_{\text {mic }}\right)$, the density measurements of copolymer solutions above their CMCs were applied using the equation [29];

$$
\rho_{\text {soln }}=\rho_{\text {solv }}+\left(1+\bar{v}_{\text {mic }} \rho_{\text {solv }}\right)(\mathrm{C}-\mathrm{cmc})
$$

Thus by plotting $\left(\rho_{\text {soln }}\right)$ versus C-cmc (Figure 5) the intercept give solvent density $\left(\rho_{\text {solv }}\right)$ and from the slope the corresponding partial specific volume of the micelle $\left(\bar{V}_{\text {mic }}\right)$ was obtained. While the micellar density, $\left(\rho_{\text {mic }}\right)$ was obtained by taking inverse of the partial specific volume of the micelle $\left(\bar{V}_{\text {mic }}\right)$. Results from density and viscosity are given in Table 4. It can be seen that there occur somewhat increase in the partial specific volume of the micelle $\left(\bar{V}_{\text {mic }}\right)$ with increasing temperature. The effect can be assigned to the expansion of E-chain of copolymer by increasing the temperature. This is also supported by the corresponding decrease in micelle density $\left(\rho_{\text {mic }}\right)$. On average $\mathrm{E}_{56} \mathrm{~B}_{19}$ has higher $\bar{V}_{\text {mic }}$ as compared to $\mathrm{E}_{58} \mathrm{~B}_{11}$, this is observed because of the longer hydrophobic block length for $\mathrm{E}_{56} \mathrm{~B}_{19}$. A normal increasing trend in the partial specific volume of the micelle $\left(\bar{v}_{\text {mic }}\right)$ with increasing temperature was observed for each copolymer. This is due to the expansion of E-chain of copolymer by increasing the temperature.

Viscosity measurements were applied to calculate the intrinsic viscosities and other useful parameters which give valuable information about the hydrodynamic properties of the micelle [40]. For that first we determine the dynamic viscosities directly from the instrument which were then converted to relative viscosities, $\eta_{\mathrm{r}}$ and to specific viscosities, $\eta_{\mathrm{sp}}=\eta_{\mathrm{r}}^{-1}$. Plotting $\eta_{\mathrm{sp} / \mathrm{C}-\mathrm{CMC}}$ versus C-CMC (Figure 6) using modified Huggins's relation, the intrinsic viscosities, $[\eta]$ for each polymer sample were obtained from the plots [41];

$$
\frac{\eta_{s p}}{\mathrm{C}-\mathrm{CMC}}=[\eta]+\mathrm{K}_{\mathrm{H}}[\eta] \mathrm{C}-\mathrm{cmc}
$$

[ $\eta$ ] was obtained from intercept and $\mathrm{K}_{\mathrm{H}}$, the intermicellar interaction parameter or solute-solvent interaction parameter from the slope. When the solution concentration approaches zero, the intrinsic viscosity can be defined as [42];

$$
[\eta]=\left(\frac{\eta_{s p}}{(\mathrm{C}-\mathrm{cmc})}\right)_{\lim C \rightarrow 0}=\ln \frac{\eta_{r}}{\mathrm{C}-\mathrm{cmc}}
$$

It was observed that Huggin's relation is not obeyed for the whole concentration region by the viscosity data. The typical concentration dependence reduced viscosities plots for the whole concentrations region is given in Figure 7. The figure shows that in dilute concentration

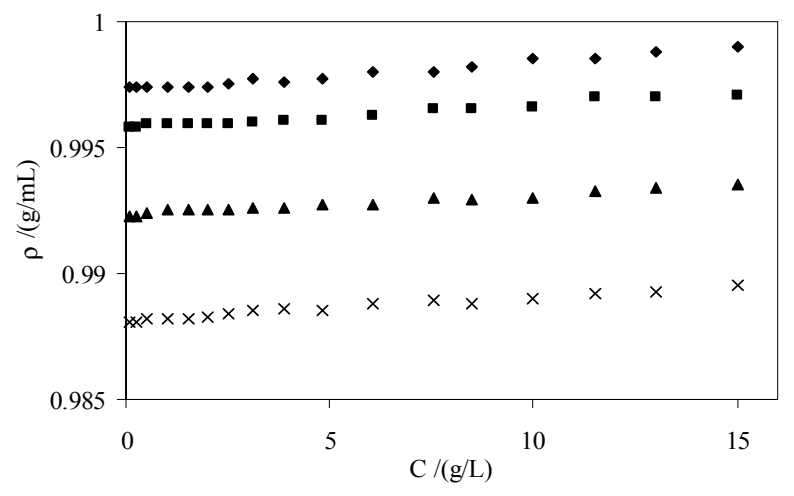

Figure 5. Plots of solution density versus $\mathrm{C}$-cme for aqueous solutions of $E_{56} B_{19}$ at temperatures $(\diamond)$ 20, ( $\square$ ) 30, ( $\Delta$ ) 40, and $(\times) 50^{\circ} \mathrm{C}$.

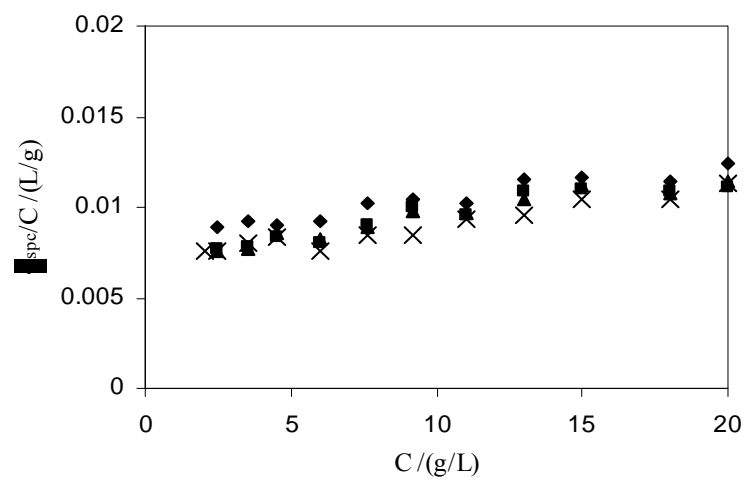

Figure 6. Typical plots of reduced versus $C$ (linear part) for aqueous solutions of E56B19 at temperatures $(\diamond)$ 20, (घ) 30, (A) 40, and $(\times) 50^{\circ} \mathrm{C}$.

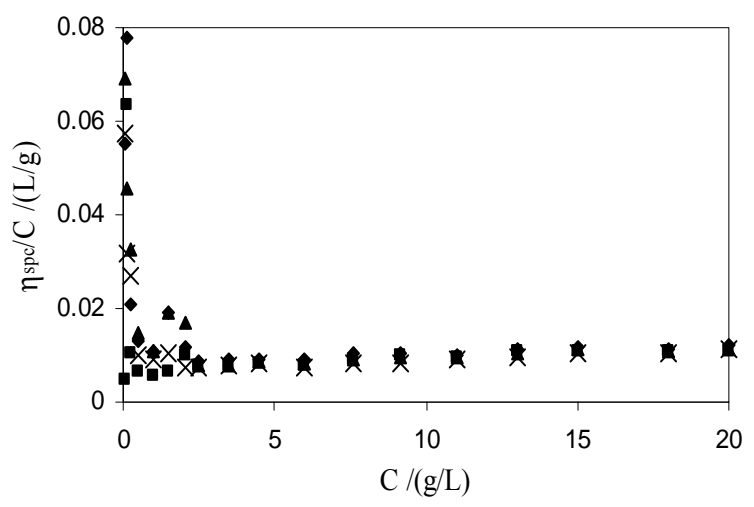

Figure 7. Typical plots of concentration dependence of reduced viscosity for aqueous solutions of E56B19 at temperatures ( $\square) 20,(\bullet) 30,(\Delta) 40$, and $(\times) 50^{\circ} \mathrm{C}$.

regime (i.e. for the concentration below $3 \mathrm{~g} \cdot \mathrm{dm}^{-3}$ ) the reduced viscosity values shoot up and a nonlinear curvature with the decrease in concentration of copolymers is observed. A similar complex dependence of reduced viscosities on concentration for diblock and triblock of poly (oxethylene)-poly(oxybutylenes) copolymers was also reported by S. Soni and co-workers [35,36]. They have 
Table 4. Micellar Density, $\rho_{\text {mic }}$, Partial Specific Volume, $\bar{\nu}_{\text {mic }}$, Intrinsic Viscosity, $[\eta]$, Interaction Parameter, $K_{\mathrm{H}}$, Hydration, $W_{h}$, Number of Water Molecules and Shape factor, $v$, for $E_{58} B_{11}$ and $E_{56} B_{19}$ in aqueous solutions at Different Temperatures.

\begin{tabular}{|c|c|c|c|c|c|c|c|c|c|}
\hline Polymer & $\mathbf{T} /{ }^{\circ} \mathbf{C}$ & $\begin{array}{c}\rho_{\text {solv }} \\
(\mathrm{g} / \mathbf{m L})\end{array}$ & $\begin{array}{c}\rho_{\text {mic }} \\
(\mathrm{g} / \mathrm{mL})\end{array}$ & $\begin{array}{c}\bar{v}_{\text {mic }} \\
(\mathrm{mL} / \mathbf{g})\end{array}$ & $\begin{array}{c}=[\eta] \\
(\mathrm{mL} / \mathrm{g})\end{array}$ & $\begin{array}{c}\mathrm{K}_{\mathrm{H}} \\
(\mathrm{mL} / \mathrm{g})\end{array}$ & $\begin{array}{l}\mathbf{W}_{\mathrm{h}}[\mathrm{g}(\text { water }) / \\
\mathbf{g}(\text { copolymer })]\end{array}$ & $\begin{array}{c}\mathrm{H}_{2} \mathrm{O} / \text { single } \\
\text { molecule }\end{array}$ & $\begin{array}{c}v=[\eta] / \\
\bar{v}\end{array}$ \\
\hline \multirow[t]{3}{*}{$\mathrm{E}_{58} \mathrm{~B}_{11}$} & 20 & 0.997 & 1.108 & 0.902 & 12.0 & 8.33 & 3.88 & 722.2 & 13.3 \\
\hline & 40 & 0.992 & 1.102 & 0.907 & 10.7 & 9.34 & 3.34 & 622.0 & 11.8 \\
\hline & 50 & 0.988 & 1.098 & 0.910 & 9.1 & 9.41 & 2.70 & 501.0 & 10.0 \\
\hline \multirow[t]{4}{*}{$\mathrm{E}_{56} \mathrm{~B}_{19}$} & 20 & 0.997 & 1.108 & 0.902 & 8.4 & 23.8 & 2.45 & 522.0 & 9.3 \\
\hline & 30 & 0.995 & 1.094 & 0.923 & 7.3 & 27.4 & 2.01 & 425.3 & 8.0 \\
\hline & 40 & 0.992 & 1.078 & 0.927 & 7.2 & 27.77 & 1.94 & 412.5 & 7.7 \\
\hline & 50 & 0.988 & 1.108 & 0.910 & 7.0 & 28.57 & 1.87 & 397.5 & 7.6 \\
\hline
\end{tabular}

Estimated uncertainities: $\pm 2 \%$ in $\rho_{\text {mic }} ; \pm 3 \% \quad \bar{V}_{\text {mic }} ; \pm 7 \%$ in $[\eta] ; \pm 9 \%$ in $\mathrm{K}_{\mathrm{H}} ; \pm 8 \%$ in $\mathrm{W}_{\mathrm{h}}$.

assigned this complex behaviour to the adsorption of the copolymers molecules on the capillary wall of viscometer, which in turn would increase the flow time and hence the measured $\eta_{\mathrm{sp}} / \mathrm{C}$ values at low concentrations are apparent. To relate the true values of reduced viscosities with those of the apparent values, Ohrn has proposed a relation [42];

$$
\left(\eta_{\mathrm{sp}} / \mathrm{C}\right) *=\eta_{\mathrm{sp}} / \mathrm{C}+\Delta \text { and } \Delta \approx\left(\eta_{\mathrm{r}} / C\right)\left(4 a_{\text {lay }} / r\right)
$$

where * indicates apparent value. The terms $a_{\text {lay }}$ and $r$ in the $\Delta$ relation are the thickness of the adsorbed layer and the radius of the capillary of the viscometer used. In this work we have used rotational viscometer with a capillary size of $0.300 \mathrm{~mm}$. For very dilute solutions $\eta_{\mathrm{r}}$ close to unity, so $\eta_{\mathrm{sp}} / \mathrm{C}$ values can be estimated by changing the chosen values for adsorbed layer thickness. In the present case the thickness of adsorbed layer was approximated to be nearly, $0.00021,0.00025,0.00027$ and 0.00031 at $20^{\circ} \mathrm{C}, 30^{\circ} \mathrm{C}, 40^{\circ} \mathrm{C}$ and $50^{\circ} \mathrm{C}$ respectively for both the copolymers. This shows that adsorption effect is increased at higher temperature.

To obtain the values of intrinsic viscosities $[\eta]$ and Huggin's parameter $\left(\mathrm{K}_{\mathrm{H}}\right)$, we have applied the linear portion of reduced viscosities versus concentration plots, as shown in Figure 6. The calculated values of $[\eta]$ and $\mathrm{K}_{\mathrm{H}}$ are listed in Table 4. For both copolymers, a decreasing trend in the values of $[\eta]$ with temperature is observed; the effect can be assigned to the dehydration of the micelle at higher temperature. At a given temperature $[\eta]$ is higher for $\mathrm{E}_{58} \mathrm{~B}_{11}$ than that for $\mathrm{E}_{56} \mathrm{~B}_{19}$ it is due to relatively longer hydrophilic part of the first polymer as compared to the last one. In the present study $\mathrm{K}_{\mathrm{H}}$ is assigned to the intermicellar interaction instead of solute-solvent interaction [41]. Higher values of $\mathrm{K}_{\mathrm{H}}$ for $\mathrm{E}_{56} \mathrm{~B}_{19}$ as compared to $\mathrm{E}_{58} \mathrm{~B}_{11}$ suggest greater intermicellar interactions for more hydrophobic $\mathrm{E}_{56} \mathrm{~B}_{19}$.

In addition to the measurements of hydrodynamic vol- ume, the intrinsic viscosities are also very useful in calculating the hydration, $\mathrm{W}_{\mathrm{h}}$ gram of water associated with gram of micelle or surfactant. Thus by using the values of intrinsic viscosity, solvent density and micellar partial specific volume at a particular temperature, we have also calculated hydration of micelle applying the following relation [35];

$$
\mathrm{W}_{\mathrm{h}}=v \rho_{\text {solv }}\left(\left(\frac{[\eta]}{2.5 \bar{v}}\right)-1\right)
$$

The calculated values of $\mathrm{W}_{\mathrm{h}}$ are given in the Table 4 . It can be seen that for both polymers, the water associated with micelle decreases with increase in temperature that is at higher temperature water associated with micelle squeeze out and hence hydration of micelle decreases. In addition to this, at a given temperature the value of $\mathrm{W}_{\mathrm{h}}$ is larger for $\mathrm{E}_{58} \mathrm{~B}_{11}$ as compared to $\mathrm{E}_{56} \mathrm{~B}_{19}$, this behaviour arise due to the higher hydrophilic/hydrophobic ratio for the first copolymer compared to that of the last one. To elaborate more the contribution of $[\eta]$ to hydrodynamic properties of the micelle, we have also deduced the shape factor (v) of micelle by using the values of $[\eta], \mathrm{W}_{\mathrm{h}}$ and partial specific volume, $\bar{v}$ by using the relations [36].

$$
v=[\eta] / \bar{v}
$$

or most simply,

$$
v=[\eta] / \bar{v}
$$

Relatively higher value of $[\eta]$ predicts the nonspherical shape of the micelle; this is the supported by the shape factor values. As according to Einstein model the shape factor value for hard sphere should be 2.5 , but in our case it is far above the Einstein range. This is because the intrinsic viscosities of micelle have contribution from both the hydrophobic core as well as hydrophilic outer shell. 


\section{Conclusion}

We have studied the association and surface active behaviour of the methoxy $\left(\mathrm{CH}_{3} \mathrm{O}-\right)$ ended $\mathrm{E}_{58} \mathrm{~B}_{11}$ and hydroxyl $(-\mathrm{OH})$ ended $\mathrm{E}_{56} \mathrm{~B}_{19}$ at different temperatures in water. The surface tension results show that the adsorption at air/water interface as well as micellization in the bulk of solution are spontaneous and temperature dependent. Lower values of $\mathrm{CMC}$ for $\mathrm{E}_{58} \mathrm{~B}_{11}$ as compared to $\mathrm{E}_{56} \mathrm{~B}_{19}$ can be attributed to increase in hydrophobicity due to $\mathrm{CH}_{3} \mathrm{O}$ group at the hydrophilic end of the $\mathrm{E}_{58} \mathrm{~B}_{11}$. It can be concluded that surface area at air/water interface increases with increase in the length of the copolymer. Increase in area at air/water interface with temperature is due to the expansion of the copolymer at higher temperature. From thermodynamic parameters of adsorption as well as micellization, it can be concluded that adsorption at air/water interface is more spontaneous and more endothermic as compared to micellization. Viscosity and density results support the nonspherical shapes of aggregates and further deviation from spherical shape can occur at lower temperature. Using the fundamental techniques like surface tensiometry, densitometry and viscometry, one can get valuable information about the associative properties of block copolymers.

\section{Acknowledgements}

Dr. Abbas Khan and Iram Bibi are grateful to the Higher Education Commission, H. E. C., Pakistan for its financial support under IPFP and indigenous Ph.D fellowship scheme. We are highly grateful to Dr. Carin Tattershall for synthesis of these copolymers at the School of Chemistry, University of Manchester, U. K. Special thanks to Professor Dr. Peter M. Budd University of Manchester for the helpful advice.

\section{REFERENCES}

[1] J. Rao, J. Zhang, J. Xu and S. Liu, "Cononsolvency-Induced Micellization Kinetics Ofpyreneend-Labeled Diblock Copolymer of Isopropylacrylamide and Oligo (Ethylene Glycol) Methyl Ether Methacrylate Studied by StoppedFlow Light-Scattering and Fluorescence," Journal of Colloids and Interface Science, Vol. 328, 2008, pp. 196-202.

[2] M. C. Jones, H. Gao and C. Leroux, "The Influence of Polymer Topology on Pharmacokinetics: Differences between Cyclic and Linear PEGylated Poly(Acrylic Acid) Comb Polymers," Journal of Controlled Release, Vol. 132, No. 3, 2008, pp. 208-215. doi:10.1016/j.jconrel.2008.05.006

[3] C. Booth and D. Attwood, "Effects of Block Architecture and Composition on the Association Properties of Poly (Oxyalkylene) Copolymers in Aqueous Solution," Macromolecular Rapid Communications, Vol. 21, No. 9, 2000, pp. 501-527.

doi:10.1002/1521-3927(20000601)21:9<501::AID-MAR

\section{C501>3.0.CO;2-R}

[4] W. Loh, "Encyclopedia of Surface and Colloid Science," In: A. T. Hubbard, Ed., Marcel Dekker, New York, 2002, pp. 802-813.

[5] W. Hamley, "The Physics of Block Copolymers," Oxford University Press, Oxford, 1998.

[6] K. Yu and A. Esenberg, "Bilayer Morphologies of SelfAssembled Crew-Cut Aggregates of Amphiphilic PS- $b$ PEO Diblock Copolymers in Solution," Macromolecules, Vol. 31, No. 11, 1998, pp. 3509-35918. doi:10.1021/ma9714191

[7] G. J. Liu, "Functional Nanostructures of Block Copolymers," Chinese Journal of Polymer Science, Vol. 18, No. 3, 2000, pp. 255-262.

[8] J. P. Spatz, T. Herzog, S. Mobmer, P. Ziemann and M. Moller, "Micellar Inorganic-Polymer Hybrid Systems-A Tool for Nanolithography," Advanced Materials, Vol. 11, No. 2, 1999, pp. 149-153.

doi:10.1002/(SICI)1521-4095(199902)11:2<149::AID-A DMA149>3.0.CO;2-W

[9] S. A. Jenekhe and X. L. Chen, "Self-Assembled Aggregates of Rod-Coil Block Copolymers and Their Solubilization and Encapsulation of Fullerenes," Science, Vol. 279, No. 5358, 1998, pp. 1903-1907. doi:10.1126/science.279.5358.1903

[10] M. Iijma, Y. Nagasaki, T. Okada, M. Kato and K. Kataoka, "Core-Polymerized Reactive Micelles from Heterotelechelic Amphiphilic Block Copolymers," Macromolecules, Vol. 32, No. 4, 1999, 1140-1146. doi:10.1021/ma9815962

[11] U. Otsuka, Y. Nagasaki, K. Kataoka, T. Okano and Y. Sakurai, "Reactive-PEG-Polylactide Block Copolymer for Tissue Engineering," Polymer Prepr, Vol. 9, No.2, 1998, 128-129.

[12] J. Yuan, Z. Xu, S. Cheng and L. Feng, "The Aggregation of Polystyrene- $b$-Poly(Ethylene Oxide)- $b$-Polystyrene Triblock Copolymers in Aqueous Solution," European Polymer Journal, Vol. 38, No. 8, 2002, pp. 1537-1546. doi:10.1016/S0014-3057(02)00025-3

[13] C. Booth, G. E. Yu and V. M Nace, "Amphiphilic Block Copolymers: Self-Assembly and Applications," In: P. Alexandridis and B. Lindman, Eds., Elsevier, Amsterdam, 2000.

[14] C. Booth, D. Attwood and C. Price, "Self-Association of Block Copoly(Oxyalkylene)S in Aqueous Solution. Effects of Composition Block Length and Block Architecture," Physical Chemistry Chemical Physics, Vol. 8, No. 31, 2006, pp. 3612-3622. doi:10.1039/b605367j

[15] P. Alexandridis, "Poly(Ethylene Oxide)/Poly(Propylene Oxide) Block Copolymer Surfactants," Current Opinion in Colloid and Interface Science, Vol. 2, No. 5, 1997, pp. 478-489. doi:10.1016/S1359-0294(97)80095-7

[16] E. Castro, P. Tabooda and V. Mosquera, "Behavior of a Styrene Oxide-Ethylene Oxide Diblock Copolymer/Surfactant System: A Thermodynamic and Spectroscopy Study," Journal of Physical Chemistry B, Vol. 109, No. 12, 2005, pp. 5592-5599. doi:10.1021/jp044766n

[17] X. Li, S. D. Wettig and R. E. Verrall, "Isothermal Titra- 
tion Calorimetry and Dynamic Light Scattering Studies of Interactions between Gemini Surfactants of Different Structure and Pluronic Block Copolymers," Journal Colloid and Interface Science, Vol. 282, No. 2, 2005, pp. 466-477. doi:10.1016/i.jcis.2004.08.153

[18] J. Mata, T. Joshi, D. Varade, G. Ghosh and P. Bahadur, "Aggregation Behavior of a PEO-PPO-PEO Block Copolymer + Ionic Surfactants Mixed Systems in Water and Aqueous Salt Solutions," Colloids and Surfaces A: Physicochemical and Engineering Aspects, Vol. 247, No. 1-3, 2004, pp. 1-7. doi:10.1016/i.colsurfa.2004.07.011

[19] H. Desai, D. Varade, V. K. Aswal, P. S. Goyal and P. Bauhau, "Micellar Characteristics of Diblock Polyacrylate-Polyethylene Oxide Copolymers in Aqueous Media," European Polymer Journal, Vol. 42, No. 3, 2006, pp. 593-601. doi:10.1016/j.eurpolymj.2005.08.016

[20] N. Jain, V. K. Aswal, P. S. Goyal and P. Bahadur, "Salt Induced Micellization and Micelle Structures of PEO: PPO: PEO Block Copolymers in Aqueous Solution," Colloids and Surfaces A, Vol. 173, No. 1, 2000, pp. 85-94. doi:10.1016/S0927-7757(99)00514-2

[21] E. Castro, P. Tabooda and V. Mosquera, "Cosolvent Effects on the Micellization of Oxyphenyl(copoly)ethylene Oxide Copolymers in Aqueous Solution," Journal of Physical Chemistry B, Vol. 110, No. 26, 2006, pp. 1311313123. doi:10.1021/jp061322d

[22] R. Ganguly, V. K. Aswal, P. A. Hassan, I. K. Gopalakrishnan and J. V. Yakhmi, "Sodium Chloride and Ethanol Induced Sphere to Rod Transition of Triblock Copolymer Micelles," Journal of Physical Chemistry B, Vol. 109 , No. 12 , 2005, pp. 5653-5658. doi:10.1021/jp0468408

[23] A. Kelarakis, S. M. Mai, V. Havredaki, V. M. Nace and C. Booth, "Effect of End Group on the Micelle Properties of Diblock Copolymers of Ethylene Oxide and 1,2-Butylene Oxide," Physical Chemistry Chemical Physics, Vol. 3, 2001, pp. 4037-4043. doi:10.1039/b105515c

[24] M. Maskos, "Influence of the Solvent and the End Groups on the Morphology of Cross-Linked Amphiphilic Poly (1,2-Butdiene)-b-poly(ethylene oxide) Nanoparticles," Polymer, Vol. 47, 2006, pp. 1172-1178. doi:10.1016/i.polymer.2005.12.045

[25] C. E. Tattershall, N. P. Jerome and P. M. Budd, "Oxyethylene/Oxybutylene Block Copolymers as StructureDirecting Agents in the Preparation of Mesoporous Silica," Journal of Materials Chemistry, Vol. 11, 2001, pp. 2979-2984. doi:10.1039/b105484h

[26] M. Siddiq, W. Harrison, C. E. Tattershall and P. M. Budd, "Micelle Properties of a Dimethylamino- and a Trimethylammonium-Tipped Oxyethylene-Oxybutylene Diblock Copolymer in Water," Physical Chemistry Chemical Physics, Vol. 5, No. 18, 2003, pp. 3968-3972. doi:10.1039/b306624j

[27] M. J. Rosen, "Surfactants and Interfacial Phenomenon," Wiley Inter Science Publication, New York, 1978, pp. 83-122.

[28] S. Barbosa, M. A. Cheema, P. Taboada and V. Mosquera, "Effect of Copolymer Architecture on the Micellization and Gelation of Aqueous Solutions of Copolymers of
Ethylene Oxide and Styrene Oxide," The Journal of Physical Chemistry B, Vol. 111, No. 37, 2007, pp. 1092010928. doi:10.1021/jp073481i

[29] A. Khan and M. Siddiq, "Surface Activity and Micellar Behavior of Dimethylaminoand TrimethylammoniumTipped Oxyethylene-Oxybutylene Diblock Copolymers in Aqueous Media," Journal of Applied Polymer Science, Vol.118, No. 6, 2010, pp. 3324-3332. doi:10.1002/app.32226

[30] T. P. Lodge, "Block Copolymers: Past Successes and Future Challenges," Macromolecular Chemistry and Physics, Vol. 2, 2003, pp. 265-273. doi:10.1002/macp.200290073

[31] P. Alexandridis, V. Thanassiou, S. Fukuda and T. A. Haton, "Surface Activity of Poly(ethylene oxide)-blockPoly(propylene oxide)-block-Poly(ethylene oxide) Copolymers," Langmuir, Vol. 10, 1994, pp. 2604-2612. doi:10.1021/la00020a019

[32] N. K. Reddy, P. J. Fordham, D. Attwood and C. Booth, "Association and Surface Properties of Block-copoly(oxyethylene/oxypropylene/oxyethylene) L64," Journal of the Chemical Society, Faraday Transactions, Vol. 86, No. 9, 1990, pp. 1569-1572. doi:10.1039/ft9908601569

[33] S. B. Sultana, S. G. T. Bhat and A. K. Rakshit, "Studies of the Effect of Additives on the Surface and Thermodynamic Properties of Poly(oxyethylene(10)) Lauryl Ether in Aqueous Solution," Langmuir, Vol. 13, No. 17, 1997, pp. 4562-4568. doi:10.1021/la960527i

[34] P. L. Nostro and G. Gabrielli, "Temperature and Subphase Effects on Aliphatic Alcohol Films at the Air- Water Interface," Langmuir, Vol 9, No. 11, 1993, pp. 31323137. doi:10.1021/la00035a063

[35] S. S. Soni, N .V. Sastry, A. K. Patra, J. V. Joshi and P. S. Goyal, "Surface Activity, SANS, and Viscosity Studies in Aqueous Solutions of Oxyethylene and Oxybutylene Diand Triblock Copolymers," The Journal of Physical Chemistry B, Vol. 106, No. 50, 2002, pp. 13069-13077. doi:10.1021/jp026277y

[36] S. S. Soni, N. V. Sastry, V. K. Aswal and P. S. Goyal, "Micellar Structure of Silicone Surfactants in Water from Surface Activity, SANS and Viscosity Studies," The Journal of Physical Chemistry B, Vol. 106, No. 10, 2002, pp. 2606-2617. doi:10.1021/jp0129434

[37] M. J. Rosen, A. W Cohen, M. Dahanayeke and X.-Y. Hua, "Relationship of Structure to Properties in Surfactants. 10. Surface and Thermodynamic Properties of 2-Dodecyloxypoly(ethenoxyethanol)s, $\mathrm{C}_{12} \mathrm{H}_{25}\left(\mathrm{OC}_{2} \mathrm{H}_{4}\right) \mathrm{xOH}$, in Aqueous Solution," The Journal of Physical Chemistry, Vol. 86, 1982, pp. 541-545. doi:10.1021/j100393a025

[38] D. G. Hall, "Nonionic Surfactants Physical Chemistry," In: M. J. Schick, Ed., Marcel Dekker, New York, 1987, pp. 23-247.

[39] Z. Zhou and B. Chu, "Phase Behavior and Association Properties of Poly(oxypropylene)-Poly(oxyethylene)-Poly(oxyprop ylene) Triblock Copolymer in Aqueous Solution," Macromolecules, Vol. 27, 1994, pp. 2025-2033. doi:10.1021/ma00086a008 
[40] M. A. Abed, A. Saxena and H. B. Bohidar, "Micellization of Alpha-Olefin Sulfonate in Aqueous Solutions Studied by Turbidity, Dynamic Light Scattering and Viscosity Measurements," Colloids and Surfaces A: Physiochemical and Engineering Aspects, Vol. 233, No. 1-3, 2004, pp. 181-187. doi:10.1016/j.colsurfa.2003.11.016

[41] A. Khan, G. F. Durrani, M. Usman, W. Harrison and M. Siddiq, "Effect of the Hydrophilic Block Length on the Micellar Properties of Oxyethylene-Oxybutylene Diblock
Copolymers in Aqueous Solution: Density and Viscosity Studies," Journal of the Chemical Society of Pakistan, Vol. 31, 2009, pp. 731-737. doi:10.1002/pol.1955.120178317

[42] O. E. Ohrn, "Preliminary Report on the Influence of Adsorption on Capillary Dimensions of Viscometers," Journal of Polymer Science, Vol. 17, No. 83, 1955, pp. 137140. 